Vol. 30, julho 2014, http://dx.doi.org/10.5380/dma.v30i0.33029

\begin{tabular}{l|l} 
SISTEMA \\
ELETRONICO \\
DE REVISTAS \\
SER I UfPR \\
unw.ser.ufpr.br \\
DESENVOLVIMENTO
\end{tabular}

\title{
Instituições para regulação ambiental: o processo de licenciamento ambiental em quatro países produtores de hidreletricidade
}

\section{Institutions for Environmental Regulation: the Environmental Licensing Process in Four Countries Producers of Hydroelectricity}

\author{
Priscilla Melleiro PIAGENTINI ${ }^{1}$, Arilson da Silva FAVARETO ${ }^{2}$ \\ ${ }^{1}$ Doutora em Energia (UFABC). E-mail: pmpiagentini@uol.com.br \\ ${ }^{2}$ Doutor em Ciência Ambiental (USP). Professor da Universidade Federal do ABC (UFABC). E-mail: arilson@uol.com.br
}

Artigo: Recebido em: 13 de agosto de 2013; Versão final aceita em: 21 de março de 2014.

RESUMO Nas décadas finais do século XX, o cenário de degradação ambiental impulsionou o estabelecimento de normas e instrumentos que condicionam a viabilidade de obras de infraestrutura à análise de aspectos socioambientais, além dos técnico-econômicos comumente avaliados. A Avaliação de Impactos Ambientais (AIA) é um destes instrumentos. Este artigo traz uma análise comparativa dos processos de licenciamento de usinas hidrelétricas no Brasil, Estados Unidos, Canadá e China. O objetivo é avaliar as ferramentas adotadas no planejamento energético em perspectiva comparada, com o intuito de identificar eventuais aprendizados que poderiam ser absorvidos pelo arcabouço institucional brasileiro. Por meio desta análise, é possível verificar que os processos de licenciamento dos distintos países se assemelham em suas origens, avanços, estrutura e deficiências. Contudo, os resultados obtidos evidenciam também aspectos que podem ser adotados para a realidade brasileira, visando ao aperfeiçoamento dos marcos institucionais da regulação ambiental em vigor.

Palavras-chave: hidroeletricidade; avaliação de impactos; recursos naturais.

ABSTRACT In the final decades of the twentieth century, the scenario of environmental degradation spurred the establishment of standards and instruments that affect the viability of infrastructure for the analysis of environmental aspects in addition to the technical and economical aspects commonly evaluated. The Environmental Impact Assessment (EIA) is one of these instruments. The article presents a comparative analysis of the licensing process for hydroelectric plants in Brazil, the United States, Canada and China. The objective is to evaluate the tools used in energy planning in comparative perspective, in order to identify lessons that could be absorbed by the Brazilian institutional framework. Through this analysis, it is possible to verify that the processes of environmental licensing in different countries are similar in their origins, developments, structure and defects. However, lessons can be drawn for the Brazilian reality in view of the results and the need for strengthening this institutional frame.

Keywords: hydroelectricity; impact assessment; natural resources. 


\section{Introdução}

Boa parte da energia elétrica mundial é gerada por fontes térmicas e nucleares. Seus usos, porém, são questionados por comprometerem a qualidade dos recursos naturais. Tal fato abre caminho para a diversificação da matriz elétrica por meio da inserção de outras fontes de energia, consideradas renováveis e menos poluentes, como a hídrica, a eólica, a solar e a biomassa. Entretanto, as vantagens destas fontes não extinguem as possibilidades de ocorrência de impactos que não estejam diretamente relacionados à poluição. A hidreletricidade, por exemplo, mesmo sendo menos poluente e renovável, gera impactos, como alterações no equilíbrio dos ecossistemas e, também, no modo de vida de populações tradicionais (WCD, 2000; Zhouri \& Oliveira, 2007).

Os impactos associados às fontes hídrica, térmica e nuclear distinguem-se entre si por sua natureza, magnitude e significância, o que por sua vez também depende da região onde se pretende instalá-las. Isto torna complexo o processo de definição e escolha das melhores fontes para atender aos requisitos de expansão de oferta energética e, ao mesmo tempo, minimizar impactos ambientais negativos.

A Avaliação de Impactos Ambientais (AIA) surge neste cenário como ferramenta importante para assegurar a proteção ambiental e, também, para auxiliar o planejamento das formas de uso de recursos naturais (Sánchez, 2008). Mesmo com os avanços verificados nas décadas recentes, existem lacunas técnicas, administrativas e regulatórias em processos de licenciamento ambiental que precisam ser identificadas e minimizadas. Do ponto de vista técnico, a qualidade dos estudos de impacto ambiental é um exemplo. Há, aqui, dois problemas, sucintamente apresentados a seguir.

O primeiro é o relativo desconhecimento que ainda paira sobre certas dimensões dos impactos ambientais de obras como grandes usinas hidrelétricas. Muito embora seja verdade que estes impactos vêm sendo cada vez mais percebidos a partir da atuação de movimentos ambientalistas, de organizações representativas das populações afetadas e mesmo de estudiosos do tema (Acselrad, 2004), também é fato que, especificamente sobre os impactos nos ecossistemas, ainda há uma enorme controvérsia sobre a extensão de seu alcance e como monitorá-los.

O segundo problema, em certa medida ligado ao primeiro, mas com certo grau de independência, tem a ver com o caráter relativamente superficial de muitos estudos de impacto ambiental (Sevá, 2008; Abramovay, 2010). E, aqui, dois fatores merecem destaque: de um lado, o já mencionado problema relativo ao conhecimento imperfeito sobre o funcionamento dos ecossistemas contribui para que o tratamento do tema seja pouco consistente nos estudos de impacto; por outro lado, muitos estudos são elaborados visando "destravar o empreendimento". Isto é, não são elaborados para efetivamente avaliar os impactos e a viabilidade dos projetos, mas sim para prever que ações de compensação ou mitigação podem ser a eles combinadas para que os investimentos previstos não sejam bloqueados.

Estas incertezas e imperfeições, associadas a problemas relativos ao rito decisório - como a precariedade de formas de participação social ou os conflitos de interesses entre partes envolvidas no ritual de licenciamento -, fazem com que estes processos sejam marcados por morosidade, altos custos de transação e alto grau de contestabilidade social.

Em tal contexto, é imperativo interrogar em que medida os processos de licenciamento ambiental, tal como vêm sendo conduzidos, cumprem seus requisitos em servir como um instrumento de regulação das relações entre sociedade e natureza, especificamente no que diz respeito em avaliar e autorizar ou interditar investimentos a partir da mensuração de seu impacto ambiental. Esta pergunta se torna ainda mais importante quando considerado que o arcabouço institucional dos processos de licenciamento ambiental no Brasil tem em torno de trinta anos de existência, e em outros países, como nos Estados Unidos, nação precursora da AIA, mais de quarenta anos. Um exame sobre a maneira como o licenciamento ambiental brasileiro vem sendo feito, em contraste com a experiência internacional sobre o mesmo tema, pode, portanto, ser extremamente útil no sentido de iluminar aspectos dos quais o Brasil pode se beneficiar num processo de aprendizagem institucional e aperfeiçoamento dos seus marcos regulatórios.

Para responder a esta pergunta, o artigo busca identificar como a AIA acontece em alguns dos principais 
países produtores de hidreletricidade e qual seu papel no processo de tomada de decisão sobre a viabilidade de grandes obras de infraestrutura. Além do Brasil, são analisados os casos de Estados Unidos, China e Canadá. O caso dos Estados Unidos é analisado por ser esta uma nação pioneira na instrumentalização da AIA. Brasil, Canadá e China são analisados por serem os maiores produtores de hidreletricidade no mundo e por razões ambientais e geopolíticas. O Brasil e a China são duas potências emergentes e nas quais o tema energia está no centro das estratégias políticas e empresariais. E o Canadá, uma sociedade dividida quanto ao tema da mitigação dos efeitos climáticos, tem uma trajetória de posições progressistas no campo ambiental, embora seja responsável por altas emissões de gases relacionadas ao setor de transportes e ao uso intensivo de aquecimento, além de um expressivo crescimento recente da produção de petróleo a partir de areias betuminosas.

A hipótese que se pretende demonstrar é que, nos vários casos, há problemas similares aos vistos no caso brasileiro: o ritual de licenciamento é meramente autorizativo e apresenta sérios limites como instrumento de debate público sobre os impactos ambientais e sobre os custos envolvidos na opção por realizar os empreendimentos em questão. Além de evidenciar quais são estes limites - cujo desdobramento implica a necessidade de rever os termos em que ocorrem os processos de licenciamento, aperfeiçoando-os -, o artigo identifica aspectos específicos da experiência de cada país que, se considerados de forma combinada, podem permitir a inauguração de uma nova geração de dispositivos institucionais para os processos de licenciamento no Brasil, mais condizentes com a trajetória de aprendizado e com as reais necessidades de se equilibrar a crescente demanda por energia com processos mais eficientes de consulta pública em torno de empreendimentos voltados a este fim.

Para isto, o artigo está organizado da seguinte maneira. A primeira seção traz um panorama geral sobre as fontes de geração de energia elétrica no Brasil e no mundo, com ênfase à geração hidrelétrica. $\mathrm{O}$ intuito aqui é mostrar a magnitude do problema e o quão crucial é enfrentar o tema do aperfeiçoamento dos marcos regulatórios da legislação ambiental voltada aos grandes empreendimentos. A segunda seção avalia a situação que envolve a produção de hidreletricidade e os processos de licenciamento ambiental nos países selecionados: Estados Unidos, Brasil, China e Canadá. Ao final, a conclusão retoma as evidências empíricas e a hipótese anunciada, destacando as principais contribuições da análise empreendida para o aperfeiçoamento dos processos de licenciamento no Brasil.

\section{Breve panorama sobre a eletricidade no mundo}

O aumento da demanda por energia elétrica e as formas pelas quais a energia é convertida constituem temas presentes em debates mundiais, especialmente em virtude dos impactos ambientais e sociais intrínsecos, qualquer que seja a fonte. Esta seção discorre sobre as formas de geração de energia elétrica no mundo e o papel da hidreletricidade neste contexto.

A matriz elétrica mundial é estruturada a partir das características e peculiaridades de cada nação - por exemplo, segundo o tipo e a disponibilidade de recursos naturais. Em grande parte dos países, a energia elétrica é gerada por fontes não renováveis, especialmente as térmicas, a partir do uso de combustíveis fósseis, com $67,7 \%$, e as nucleares, com 13,5\% (Brasil, 2011). Em 2007, na China, os combustíveis fósseis foram responsáveis por $77,7 \%$ da oferta interna de energia elétrica. Do restante, $20,3 \%$ vem da hidreletricidade e $1,2 \%$ da fonte nuclear (Hong et al., 2009). Por sua vez, em países que detêm condições hidrológicas favoráveis, a matriz se inverte, com uso prioritário da hidreletricidade, caso do Brasil, com 80\%, e do Canadá, com 60\% (EUA, 2010).

Os impactos relacionados à emissão de gases de efeito estufa (GEE) vêm favorecendo a diversificação da matriz elétrica (Walter, 2007). Estudos indicam que nos últimos trinta anos esta diversificação se caracterizou pelo decréscimo da participação hídrica e de combustíveis fósseis e pelo acréscimo da participação do gás natural, do urânio e da biomassa, além de outras renováveis, como a eólica e a solar (Brasil, 2011). Nesse quadro, a produção e o uso de energia são responsáveis por mais de $60 \%$ das emissões de GEE em todo o mundo (Walter, 2007; Hong et al., 2009). 
Para cumprir compromissos políticos estabelecidos em convenções internacionais e para satisfazer a contestação social aos impactos ambientais no âmbito da produção de energia elétrica, algumas nações passaram a buscar alternativas que contribuíssem para o cumprimento de metas de redução de emissões. Uma delas é o investimento no uso de tecnologias limpas, renováveis e que possam reduzir a dependência por combustíveis fósseis, caso da hidreletricidade (Truchon, 2006). Ocorre que as usinas hidrelétricas podem emitir GEE em pequenas ou grandes quantidades, que variam em função das características do reservatório e da sua localização. Estudos recentes revelam que usinas hidrelétricas podem emitir mais GEE que usinas termelétricas quando instalados grandes reservatórios em regiões tropicais (Raadal et al., 2011; Steinhurst et al., 2012). Além disso, a construção de usinas pode levar a mudanças no uso do solo que favorecem a emissão de GEE, à perda de biodiversidade, caso típico da exploração hidrelétrica na Amazônia, e pode gerar impactos sociais, como deslocamentos involuntários de populações atingidas (WCD, 2000; Sánchez, 2008).

Especificamente quanto à necessidade de redução de emissões, instituições passaram a apostar no uso das fontes renováveis, como a hidreletricidade. Truchon (2006) destaca algumas passagens. Em 2003, em Kyoto (Japão), durante o $3^{\circ}$ Fórum Mundial sobre a Água, ficou estabelecido que a hidreletricidade representa papel importante no desenvolvimento sustentável por ser fonte renovável e limpa de energia. No ano seguinte, em Bonn (Alemanha), na $1^{\text {a }}$ Conferência Internacional de Energia Renovável, a hidreletricidade é confirmada como fonte importante de energia renovável. Ainda em 2004, em Beijing (China), durante o $1^{\circ}$ Simpósio de Hidreletricidade e Desenvolvimento Sustentável, as autoridades reafirmaram a importância estratégica da hidreletricidade para o desenvolvimento sustentável. No ano de 2006, em Johannesburg (África do Sul), durante a Conferência Ministerial de Hidreletricidade e Desenvolvimento Sustentável, solicita-se colaboração para o melhor aproveitamento do potencial hidrelétrico da África. Ainda em 2006, na Cidade do México (México), durante o $4^{\circ}$ Fórum Mundial sobre a Água, reafirma-se a importância da água para todos os aspectos do desenvolvimento sustentável, incluindo o uso da energia hídrica.
Quando se olha para os números em escala planetária, esta importância fica ainda mais evidente. Cerca de $20 \%$ da eletricidade do mundo é produzida por energia hidráulica (Hinrichs et al., 2010). Estudos estimam que a capacidade hidrelétrica global instalada, que em 2011 era de $1.067 \mathrm{GW}$, pode atingir os $1.680 \mathrm{GW}$ em 2035. Grande parte deste incremento se deve ao aumento da capacidade na China, Índia, Brasil e África nos últimos anos (EUA, 2012a). Segundo a International Energy Agency - IEA, em 2010 os maiores produtores de hidreletricidade foram China (20,5\%), Brasil (11,5\%), Canadá (10\%) e EUA $(8,1 \%)$. Estas nações são responsáveis pela produção de $50 \%$ da energia hidrelétrica mundial (EUA, 2012b).

Todo este cenário sugere que, apesar da contestabilidade em torno dos impactos socioambientais inegáveis, a hidreletricidade tende a continuar sendo importante alternativa para produção de energia elétrica. Isto reforça a importância de se compreender de que maneira as formas de exploração deste recurso podem ocorrer com menores impactos.

\section{Hidreletricidade e a avaliação de impactos ambientais}

Esta seção apresenta os aspectos gerais que delineiam o processo de AIA nos Estados Unidos, Brasil, Canadá e China. Passados um pouco mais de quarenta anos, a AIA é hoje mundialmente reconhecida como instrumento para a gestão ambiental que permite incorporar aspectos e impactos ambientais na análise de viabilidade de projetos, de maneira a auxiliar a tomada de decisão (Morgan, 2012). Previamente à adoção da AIA, a viabilidade de um projeto era expressa por meio do balanço entre custos e benefícios, levando-se em consideração aspectos econômicos e financeiros, como a lucratividade do empreendimento (Reis, 2011).

Tem-se na Conferência de Estocolmo, ocorrida em 1972, um marco de mudança (La Rovere, 2001). Segundo o autor, as possíveis consequências negativas da ação humana sobre os ecossistemas levaram a uma maior conscientização sobre a necessidade de se estabelecer padrões ambientais de qualidade. Na visão de Sánchez (2008), a instrumentalização da AIA é resultado do processo político que buscou atender uma demanda social, 
iniciada nos EUA ainda no final dos anos 60, de problemas ambientais similares entre as nações e da atuação de agências bilaterais de fomento ao desenvolvimento, como a U.S. Agency for International Development USAID, Organização das Nações Unidas - ONU, do Banco Mundial - BIRD - e do Banco Interamericano de Desenvolvimento - BID (Rocha et al., 2005). Dentre os países mais ricos, os Estados Unidos (1969-70), o Canadá (1973) e a Nova Zelândia (1973) foram os pioneiros. Para os demais países, a necessidade de obtenção de empréstimos junto a organismos internacionais foi o fator alavancador da AIA, caso pioneiro da Colômbia, que já em 1974 incluía provisões sobre AIA em seus regulamentos (Sánchez, 2008).

Globalmente, a AIA e o licenciamento ambiental ocorrem simultaneamente e são amparados na elaboração de Estudos de Impacto Ambiental - EIA - quando o empreendimento ou atividade pretendidos são potencialmente causadores de significativa degradação ambiental. Normalmente, estes estudos são instrumentos utilizados durante a etapa de projeto do empreendimento para a identificação e avaliação de impactos ambientais. Para Morgan (2012), mesmo com os avanços, a AIA teve um poder de influência menor do que o previsto ao longo das últimas décadas, devido à dificuldade em se conciliar a política nacional, o processo de tomada de decisão e os acordos internacionais. Segundo o autor, as deficiências do processo de AIA refletem uma política moldada por aqueles que determinam quais objetivos devem ser atingidos. No âmbito da AIA, as experiências recentes confirmam que há margem considerável para o fortalecimento do processo, principalmente se a atuação focar quatro áreas: (i) revisão do significado da AIA, devido à pouca atenção dada à sua base conceitual; (ii) escopo; (iii) revisão dos estudos; e (iv) monitoramento.

Segundo Li (2008), as etapas do processo de licenciamento ambiental são mundialmente semelhantes e envolvem a elaboração do estudo ambiental propriamente dito, a análise do órgão licenciador, a participação pública, a tomada de decisão e o acompanhamento da instalação e da operação. Mesmo apresentando mesma estrutura e finalidade, diferentes nações conduzem o processo de licenciamento ambiental com nuances, face às características de cada região, de cada ambiente político-institucional e conforme a importância dada às questões socioambientais pelos tomadores de decisão. Os itens a seguir destacam características marcantes do processo de licenciamento ambiental nos Estados Unidos, Brasil, Canadá e China.

\subsection{Estados Unidos da América-EUA}

Segundo a IEA, em 2010 os EUA eram o quarto maior produtor de hidreletricidade do mundo (286 TWh ou $8,19 \%$ da produção total mundial). A capacidade instalada é de $100 \mathrm{GW}$ (EUA, 2012b). Mais da metade da capacidade hidrelétrica dos EUA está concentrada em três estados americanos: Washington, Califórnia e Oregon. Cerca de 30\% do total de hidreletricidade é gerada em Washington, onde está localizada a maior usina hidrelétrica do país, a Grand Coulee Dam, com capacidade de geração de 6,8 GW (Ortolano \& Cushing, 2000). Os EUA concentram mais de oitenta mil barragens. Porém, pouco mais de cinco mil são utilizadas para a geração de energia elétrica. A maior parte das barragens americanas foi construída para o controle de cheias, irrigação e recreação. Com vistas ao incremento da produção de energia elétrica no país, estudos conduzidos pela National Hydropower Association - NHA - indicam que podem ser adicionados equipamentos de geração de energia nas barragens já existentes, o que contribuiria para o aumento da capacidade hidrelétrica sem a necessidade de construção de novos barramentos, o que poderia minimizar a ocorrência de impactos ambientais relacionados à construção (Bermann, 2007). Segundo a NHA, as cem maiores barragens podem prover um incremento de $8 \mathrm{GW}$.

Os EUA foram os precursores na incorporação formal da AIA como instrumento legal (Morgan, 2012). Em 1969, foi sancionada a National Environmental Policy Act - NEPA, a política ambiental americana que entrou em vigor em 1970. A lei cria o Conselho de Qualidade Ambiental (Council Environmental Quality - CEQ) como instituição responsável pela definição de programas, regras e procedimentos para a AIA, entre eles a apresentação de uma Declaração de Impacto Ambiental (Environmental Impact Statement - EIS) à sociedade (Webb \& Sigal, 1992). Uma das intenções da NEPA foi inserir a questão ambiental na determinação da viabili- 
dade ambiental de projetos, ainda na sua etapa de planejamento, quando ainda é possível destacar o potencial de impactos associados e analisar alternativas (Webb \& Sigal, 1992). O objetivo é identificar impactos ambientais da ação proposta, efeitos adversos, alternativas de ação e medidas de mitigação e possíveis irreversibilidades de recursos envolvidos na ação (Rocha et al., 2005).

A decisão sobre a preparação do EIS é da agência federal responsável, respaldada pelos critérios e orientações designados pelas agências multissetoriais federais envolvidas no processo. As agências responsáveis pelo cumprimento da NEPA nos EUA têm poder para fiscalizar a elaboração dos estudos ambientais em sua área de jurisdição, possibilitando a descentralização das ações. No entanto, a lei prevê que estas agências devem receber orientação da agência ambiental federal (Environmental Protection Agency - EPA).

O envolvimento público é mais expressivo entre as etapas preliminar e final de elaboração do EIS, pois permite que todos os atores afetados discutam os rumos do projeto. ANEPA assegura a participação pública ainda na etapa de definição do escopo (scoping), garantindo que os problemas sejam identificados e avaliados no início do processo (Webb \& Sigal, 1992). Durante esta etapa, é possível reunir e enfocar os itens mais relevantes, reduzindo atrasos desnecessários.

A participação pública também ocorre mediante a realização de reuniões públicas nas localidades atingidas pelo projeto, embora não seja obrigatória pela legislação. Estas reuniões são incentivadas quando existem pontos conflitantes no estudo ou quando há a solicitação por outro órgão do governo (Silva \& Soares, 2004). A versão final do EIS deve incluir os comentários do público envolvido. Todas as questões levantadas devem ser respondidas e divulgadas. Nos EUA, a empresa definida para elaboração do EIS deve apresentar uma declaração de que não tem interesses econômicos ligados à realização do projeto, de forma a minimizar parcialidades. A NEPA não prevê a elaboração de uma síntese do estudo ambiental, no Brasil denominado relatório de impacto ambiental - RIMA, mas a prática impôs tal necessidade: o equivalente do RIMA nos EUA é denominado Summary EIS (Sánchez, 2008).

Como os Estados Unidos não preveem em seu planejamento energético a construção de grandes projetos hidrelétricos, os estudos de AIA mais recentes contemplam renovações de licenças já existentes (relicensing), que também obedecem aos procedimentos estabelecidos na NEPA, com a submissão de EIS.

\subsection{Brasil}

Em 2010, o Brasil era o segundo maior produtor de hidreletricidade do mundo, mantendo uma produção de 403 TWh ou 11,5\% da produção mundial (EUA, 2012b). O potencial hídrico brasileiro é da ordem de 259 GW (EUA, 2012b) e, deste total, 177 GW (70\%) estão inventariados (operação e construção) e 82 GW (30\%) estão estimados (a aproveitar). A maior parte do potencial a ser aproveitado encontra-se na Amazônia (Brasil, 2006). Os aproveitamentos hidrelétricos (AHE) de Belo Monte (PA), Santo Antônio e Jirau (RO), previstos para operar na Bacia Amazônica, respectivamente, nos rios Xingu e Madeira, acrescentarão 17,7 GW aos 79,2 GW de potência já instalados no país, garantindo, segundo o governo, o suprimento de energia por alguns anos. Além destes, é prevista a instalação do complexo Teles Pires, na bacia de mesmo nome, que contempla a construção de seis barragens, aumentando a capacidade instalada em 3,7 GW, e do complexo Tapajós, com a instalação de sete usinas, com capacidade total de 14,2 GW. O incremento total previsto seria de cerca de 35,6 GW nos próximos anos.

O estabelecimento da AIA no Brasil decorreu tanto de exigências de instituições financeiras internacionais para concessão de créditos (Rocha et al., 2005) como de pressão social (local, mas também da comunidade científica e da opinião pública internacional) por participação e pela adoção de legislação específica para impactos ambientais. Segundo Sánchez (2008), os primeiros processos de AIA envolvendo hidrelétricas no país relacionam-se à instalação das usinas de Sobradinho, no rio São Francisco (1972), e Tucuruí, no rio Tocantins (1977). Ambas foram, em parte, financiadas pelo Banco Mundial. Entretanto, os estudos de impacto foram pouco significativos, pois foram elaborados um ano após o início das obras. Na época, não havia legislação brasileira que regulasse a AIA. 
O processo de licenciamento ambiental brasileiro é respaldado pela Política Nacional de Meio Ambiente - PNMA (Lei 6.938), em vigor desde 1981. A base legal estabelece que os empreendimentos efetiva ou potencialmente causadores de significativa degradação ambiental devem ser submetidos ao processo de licenciamento ambiental baseado em estudos de impacto ambiental. Para tanto, criou-se uma estrutura institucional capaz de fazer cumprir os objetivos da AIA: o Sistema Nacional de Meio Ambiente - SISNAMA.

Embora tenha sido formalmente estabelecida em 1981 com a publicação da PNMA, a AIA consolida-se apenas em 1986, com o início das publicações das resoluções do Conselho Nacional de Meio Ambiente - CONAMA, órgão federal consultivo e deliberativo que assessora, estuda, propõe diretrizes e delibera sobre normas e padrões sobre meio ambiente, e com a criação do Instituto Brasileiro do Meio Ambiente e dos Recursos Naturais Renováveis - IBAMA, órgão ambiental federal responsável por executar e fazer executar as políticas e diretrizes governamentais.

O processo de licenciamento ambiental brasileiro inicia-se com a solicitação da licença prévia para instalação de projeto e apresentação da proposta pelo proponente ao órgão ambiental competente, estadual ou federal, que verificará a necessidade de elaboração de um EIA-RIMA. Caso o EIA-RIMA seja necessário, elabora-se o estudo, contemplando informações sobre o diagnóstico atual da área de influência, a identificação e avaliação dos impactos positivos e negativos e a proposição de medidas mitigadoras e compensatórias. Quando concluído, o EIA-RIMAé submetido ao órgão ambiental competente, que avaliará a qualidade do documento em termos de conteúdo e atendimento ao Termo de Referência. Com o parecer positivo do órgão ambiental, o extrato do EIA (o RIMA) é submetido ao conhecimento da sociedade, que poderá expor suas dúvidas e recomendações em audiências públicas, regulamentadas pela resolução CONAMA n. 09/1987 (Brasil, 1987).

Caso o projeto seja considerado viável pelos tomadores de decisão - a decisão final cabe ao órgão licenciador -, o proponente obtém a licença prévia (LP), geralmente válida por cinco anos e que autoriza o detalhamento do projeto e do Plano Básico Ambiental (PBA), que conterá a descrição detalhada das medidas mitiga- doras e compensatórias propostas no EIA. Atendendo as condicionantes estabelecidas na LP, o empreendedor segue para uma outra etapa do licenciamento ambiental, a solicitação da licença de instalação (LI) e, posteriormente, a licença de operação (LO). O mecanismo principal de participação pública no Brasil é a audiência pública, que ocorre após a análise do EIA-RIMA pelo órgão ambiental. Dentre as deficiências do processo de participação pública tem-se o pouco tempo para análise do relatório (quarenta e cinco dias) e a dificuldade de compreensão por conta da linguagem técnica e da extensão, o que se torna um problema para a participação de minorias (Sánchez, 2008). No Brasil, o interessado pelo projeto é o responsável pela elaboração dos estudos ambientais, mediante a contratação de empresas especializadas. Tal situação traz para o processo de licenciamento dúvidas quanto à parcialidade das informações apresentadas.

\subsection{Canadá}

Em 2010, o Canadá era o terceiro maior produtor de hidreletricidade no mundo, com uma produção de 352 TWh ou $10 \%$ da produção mundial (EUA, 2012b). O país é banhado por muitos rios que fluem de áreas montanhosas para o oceano. Esta característica contribui para que a hidreletricidade seja a principal fonte de energia elétrica no país. De acordo com dados publicados pela Associação Canadense de Hidreletricidade (Canadian Hydropower Association - CHA), em 2006, a hidreletricidade respondia por $60 \%$ da produção total de energia elétrica no país e era responsável por $97 \%$ da eletricidade advinda de fonte renovável. Segundo a CHA, existem mais de quatrocentas e cinquenta usinas hidrelétricas no Canadá e as maiores capacidades instaladas situam-se nas províncias de British Columbia, Ontario, Terra Nova, Labrador, Quebec e Manitoba. Tal como nos EUA, observa-se no Canadá ações para incrementar a geração de eletricidade por meio de projetos de repotenciação de usinas, como é o caso da Waneta Hydroelectric Project, em British Columbia, onde se prevê um incremento de 435 MW (Canadá, 2009).

Para o governo canadense, a hidreletricidade, além de ser apresentada como uma fonte de energia limpa, renovável, abundante, acessível e confiável, comporta 
outras vantagens: apesar dos elevados custos de investimento inicial, ainda é viável economicamente, contribui para a criação e manutenção de empregos, gera receitas, não está sujeita à volatilidade dos custos elevados associados aos combustíveis fósseis. As emissões de GEE são $60 \%$ menores que nas usinas movidas a carvão e de 18 a $30 \%$ menores que nas usinas movidas a gás natural (Canadá, 2006). Apesar das vantagens, a participação da energia hídrica pode ser reduzida no Canadá para $45 \%$ até 2020, em função de outros impactos: há uma ênfase excessiva nos impactos locais e a desconsideração dos impactos globais relacionados às mudanças climáticas, como o aquecimento global (Canadá, 2006).

Políticas e projetos relacionados aos estudos de impacto ambiental ocorrem no Canadá desde 1974, quando o Gabinete Federal desenvolveu uma revisão das decisões sobre os impactos do meio ambiente (Mendell, 2010). Segundo Sánchez (2008), no Canadá a decisão por se estabelecer um processo de AIA se iniciou no final de 1973. No entanto, o decreto que dispõe sobre as diretrizes do processo é de 1984 e a Lei Canadense de Avaliação de Impacto Ambiental (Canadian Environmental Assessment Act - CEAA) é de 1992.

A CEAA foi estabelecida com o intuito de assegurar que os órgãos e agências competentes considerassem as questões ambientais nos processos decisórios. Dentre as propostas da lei está a busca por uma atuação mais sustentável. A CEAA é administrada pela Canadian Environmental Assessment Agency, instituição federal responsável pela administração do processo de AIA federal no Canadá. Dentre seus objetivos, destacam-se o monitoramento dos estudos ambientais e a responsabilidade por assegurar a participação pública.

No Canadá, os estudos ambientais são denominados Environmental Assessment - EA - e envolvem as etapas de construção, operação, alteração, descomissionamento e fechamento. Nos casos de projetos hidrelétricos, o processo de AIA envolve a necessidade de estudos abrangentes denominados pela lei canadense Comprehensive Study. A elaboração desses estudos pode seguir dois caminhos: painel de revisão (panel review) ou mediação (mediation).

No painel de revisão, há a possibilidade de revisão nos estudos a partir de observações feitas pela sociedade nas Audiências Públicas. A sociedade participa do painel de revisão por meio da exposição de opiniões, comentários e sugestões sobre cada item levantado no estudo, e estas intervenções são inseridas no relatório conclusivo que é encaminhado para a deliberação das autoridades competentes. Os comentários do público participante são incorporados no EA e são analisados pelas autoridades, que deverão dar publicidade ao documento. Na mediação, a avaliação do EA é auxiliada pela participação de um mediador que possa contribuir para arbitramento de possíveis conflitos. Este mediador deve atestar não ter interesses sobre o projeto que está sendo discutido e deve comprovar ter experiência e conhecimento acerca do tema. Um EA não será submetido a um mediador a menos que os atores envolvidos estejam dispostos a participar do processo.

\subsection{China}

Em 2010, a China era o maior produtor de hidreletricidade do mundo, com uma produção de $722 \mathrm{GWh}$, o que corresponde a $20,5 \%$ da produção mundial (EUA, 2012b). A economia chinesa vem crescendo acentuadamente e, com os novos projetos hidrelétricos previstos no plano de expansão chinês (12 ${ }^{\text {th }}$ Five Year Plan), que cobre o período entre 2011 e 2015, espera-se um acréscimo de $120 \mathrm{GW}$ na capacidade instalada do país. Este incremento é proveniente da instalação de quatorze usinas hidrelétricas, em construção no país desde 2003, à exceção de Três Gargantas. Dentre os quatorze projetos, o maior deles em potência é Xiluodo Dam, com 12,6 GW e previsão de início de operação em 2015. No ano de 2005, a construção de Xiloudo Dam foi interrompida pelo governo chinês devido à necessidade de elaboração da AIA. O investimento maciço em hidreletricidade demonstra a importância que a China vem atribuindo à fonte hidráulica para a geração de eletricidade, principalmente em virtude da repercussão negativa associada ao uso de combustíveis fósseis e à emissão de GEE.

A China introduziu o conceito de AIA em 1979, com a publicação da Lei de Proteção Ambiental (Environmental Protection Law - EP Law). Porém, este regulamento estabelecia apenas requisitos gerais, restando ausentes as medidas para execução. Por esta razão, tempos mais tarde uma série de regulamentos administrativos e 
diretrizes foi publicada. De forma a unificar a base legal de EIA e os sequentes regulamentos, entrou em vigor em 2003 a EIA Law, que basicamente reafirma e amplia as disposições preexistentes e regulamenta a AIA (Beyer, 2006). Após a promulgação da EIA Law, outras normas e procedimentos passaram a vigorar no país. A State Environmental Protection Agency - SEPA - é a agência ambiental nacional, vinculada ao Estado, responsável pela condução, aplicação e fiscalização da AIA.

O objetivo da EIA Law consiste na instrumentalização da estratégia do país para o desenvolvimento sustentável por meio da adoção de medidas que previnam ou reduzam as emissões de GEE. A EIA Law estabelece cinco princípios básicos da AIA: desenvolvimento sustentável, precaução, base científica para a tomada de decisão, participação pública e construção do estudo de impacto ambiental.

O processo de AIA na China envolve três níveis. Quando os impactos ambientais são mínimos, o órgão ambiental solicita a elaboração de um registro de impactos confeccionado pelo próprio proponente. Se existem dúvidas sobre a magnitude dos impactos, solicita-se o preenchimento de um formulário elaborado por consultor qualificado, que apresenta uma breve análise sobre os impactos identificados (Mc Elwee et al., 2008). Projetos que causem impactos ambientais significativos, tal qual se enquadra a hidreletricidade, são submetidos ao processo de licenciamento ambiental completo e, nestes casos, os proponentes devem submeter à análise da SEPA um relatório sobre os impactos ambientais do futuro projeto denominado Environmental Impact Statement - EIS (Beyer, 2006; Mc Elwee et al., 2008; Zhu \& Lam, 2009).

Este relatório deve contemplar informações sobre previsão e avaliação de impactos, ações preventivas e mitigadoras e conclusões sobre a avaliação ambiental. Caso o futuro projeto atinja diretamente interesses ambientais distintos, a agência ambiental competente deve obter parecer da sociedade por meio da realização de reuniões ou audiências públicas, exceto em situações consideradas pelo Estado como confidenciais. A EIA Law prevê que os questionamentos do público sejam inseridos na versão final do EIS juntamente com comentários sobre o encaminhamento dado.

A EIA Law estabelece a criação de um grupo de análises formado por representantes governamentais em todas as esferas e especialistas definidos aleatoriamente para a tomada de decisão sobre a viabilidade de um projeto. A lei prevê, ainda, que após cinco anos o estudo ambiental deve ser reapresentado para nova aprovação. Importante destacar que a EIA Law proíbe qualquer relação de interesse entre atores que participam do processo de licenciamento.

O Estado incentiva a participação pública, porém esta é restrita e dependente do tipo de projeto que está sendo avaliado. Apesar de a participação pública ser prevista nos regulamentos ambientais chineses, o governo se preocupa com as consequências negativas que a abertura do processo de decisão ao público pode trazer, temendo que esta ação estimule confusões e atritos que comprometam a autoridade do governo. Nos últimos anos, tentativas em prol de melhorias na participação pública têm sido constatadas (Zhao, 2010). As limitações da participação pública na China envolvem o contexto institucional chinês, a falta de fundos direcionados para estes processos de accountability e a população expressiva sem formas de organização social forte e capaz de se expressar como mecanismos de ação coletiva (Li, 2008).

Mesmo com um conjunto surpreendente de legislação ambiental, a China se depara com problemas relacionados à sobreposição de leis, falta de articulação entre organismos que complicam sua aplicação, e as tensões entre as bases legais ambientais e o processo de crescimento econômico.

Embora não tenha tradição de debate público nos processos decisórios, principalmente os confidenciais, o Estado chinês entende que a não participação pública pode contribuir para o aumento de críticas quanto à qualidade e eficiência das bases legais do país (Zhao, 2010).

A Tabela 1 sintetiza as informações sobre o processo de licenciamento ambiental nos quatro países estudados.

Conforme indica a Tabela 1, de maneira geral, a estrutura do processo de AIA é semelhante nas quatro nações estudadas, isto é, os estudos de impacto ambiental são obrigatórios para projetos hidrelétricos. O conteúdo destes estudos ambientais também se assemelha, especialmente quanto à necessidade de identificar e avaliar os impactos ambientais e propor medidas de mitigação ou compensação. 
TABELA 1 - Aspectos do processo de licenciamento ambiental de usinas hidrelétricas nos países estudados.

\begin{tabular}{lllll}
\hline & \multicolumn{1}{c}{ EUA } & \multicolumn{1}{c}{ BRASIL } & \multicolumn{1}{c}{ CANADÁ } & CHINA \\
\hline $\begin{array}{l}\text { Características do } \\
\text { ambiente }\end{array}$ & Ano de criação da Base & Ano de criação da & Ano de criação da & Ano de criação da Base \\
institucional & legal: 1969 & Base legal: 1981 & Base legal: 1992 & legal: 2003 \\
& Órgão Ambiental & Órgão Ambiental & Órgão Ambiental & Órgão Ambiental \\
& Federal: EPA & Federal: IBAMA & Federal: CEAA & Federal: SEPA
\end{tabular}

$\begin{array}{ll}\text { A lei prevê } & \text { A lei não prevê } \\ \text { mecanismos que } & \text { mecanismos } \\ \text { favoreçam a autonomia } & \text { que favoreçam } \\ \text { dos estudos em relação } & \text { a autonomia dos } \\ \text { aos proponentes do } & \text { estudos frente aos } \\ \text { empreendimento. } & \begin{array}{l}\text { proponentes do } \\ \text { empreendimento. }\end{array}\end{array}$

A lei prevê
mecanismos
que favoreçam a
autonomia dos estudos
frente aos proponentes
do empreendimento.

A lei prevê mecanismos que garantam a autonomia dos estudos frente aos proponentes do empreendimento. Mas há restrições a intervenções que contrariem objetivos considerados estratégicos para o país.

\begin{tabular}{llll}
\hline Licenciamento & O processo engloba & Três etapas (licenças): & O processo engloba \\
ambiental - escopo & numa mesma licença as & prévia, instalação e & numa mesma licença \\
& $\begin{array}{l}\text { etapas de instalação e } \\
\text { operação. }\end{array}$ & operação, ainda que & as etapas de instalação \\
& baseadas em um único e operação. & EIA inicial.
\end{tabular}

O processo engloba numa mesma licença as etapas de instalação e operação. Mas há necessidade de atualização do estudo após um determinado período.

\begin{tabular}{lllll}
\hline Participação pública & $\begin{array}{l}\text { Existente em todos os } \\
\text { casos. }\end{array}$ & $\begin{array}{l}\text { Existente em todos os } \\
\text { casos. }\end{array}$ & $\begin{array}{l}\text { Existente em todos os } \\
\text { casos. }\end{array}$ & $\begin{array}{l}\text { Restrita. Dependente do } \\
\text { tipo de projeto. }\end{array}$ \\
$\begin{array}{l}\text { Baseia-se em } \\
\text { publicização do EIA } \\
\text { (em versão preliminar) }\end{array}$ & $\begin{array}{l}\text { Baseia-se em } \\
\text { publicização do EIA } \\
\text { (em versão final) e em }\end{array}$ & $\begin{array}{l}\text { Baseia-se em } \\
\text { publicização do }\end{array}$ & $\begin{array}{l}\text { Comporta } \\
\text { questionamentos }\end{array}$ \\
$\begin{array}{llll}\text { e na incorporação dos } \\
\text { questionamentos em } \\
\text { relatório. }\end{array}$ & consultas públicas. & $\begin{array}{l}\text { preliminar) e em } \\
\text { consultas públicas. }\end{array}$ & $\begin{array}{l}\text { técnicos específicos } \\
\text { podem ser solicitados. } \\
\end{array}$ \\
& & Prevê a formação de & Painéis de Revisão e \\
& & Mediação. & \\
\hline
\end{tabular}

Dada a magnitude do empreendimento, o processo de licenciamento ambiental de usinas hidrelétricas envolve um número significativo de atores e, consequentemente, de conflitos, em virtude de interesses distintos. Em todos os casos estudados, a participação pública é considerada, em menor ou maior grau. Dentre os países estudados, o Canadá é o que melhor viabiliza a participação pública em função da existência de instrumentos como o painel de revisão e a mediação, além de haver disponível um sistema de informações virtual que in- corpora os questionamentos feitos pela sociedade. Nos Estados Unidos e no Canadá, os estudos ambientais são discutidos com o público previamente à sua conclusão, ao contrário do que ocorre no Brasil e na China.

As deficiências relacionadas ao processo de AIA envolvem, destacadamente, dúvidas e inseguranças quanto à abrangência e profundidade da avaliação dos impactos, uma vez que se desconhece a capacidade de suporte dos ecossistemas e detalhes de seu funcionamento. Esta deficiência é comum nos quatro países estudados, 
apesar de Estados Unidos e Canadá se destacarem positivamente por incluir avaliações de impactos cumulativos e sinérgicos. O Brasil vem apresentando esforços no sentido de melhorar a qualidade dos estudos ambientais, mas ainda aquém do que se espera.

Vale destacar ainda que as leis de AIA dos EUA, do Canadá e da China tentam assegurar alguma imparcialidade na condução dos estudos ambientais, vedando o envolvimento de partes envolvidas, especialmente proponentes e consultores que elaboram os estudos, ou instituindo a elaboração de estudos por equipes diversificadas. Preocupações como estas não ocorrem no Brasil.

\section{Considerações finais}

A AIA neste início de século XXI é uma realidade estabelecida em todo o mundo. Há uma estrutura de suporte bem desenvolvida a partir de agrupamentos profissionais, agências internacionais, agências nacionais, pesquisadores, além de outros grupos de agentes que contribuem para seu aprimoramento. Tal cenário não impede a ocorrência de deficiências que, corroborando Morgan (2012), se expressam, em boa parte dos casos, em problemas institucionais, baixos níveis de compromisso pelos interessados nos projetos e na frágil capacitação técnica para a avaliação dos estudos. Estas deficiências comprometem o cumprimento da finalidade maior da AIA, prejudicando o caráter auxiliador no processo de tomada de decisão sobre custos socioambientais de empreendimentos. Uma ameaça que, novamente segundo Morgan (2012), se acirra com a atuação dos governos na busca por viabilizar maior crescimento econômico, para o qual a expansão da infraestrutura torna-se um imperativo.

No âmbito técnico, há dificuldades de mais difícil transposição, que só poderão ser minimizadas a médio prazo, com o avanço das pesquisas científicas que permitam melhor compreender - e, como decorrência, melhor monitorar - aspectos como os efeitos sobre a capacidade de suporte dos ecossistemas, garantindo uma avaliação mais fiel dos impactos negativos gerados pelas alterações ambientais e maior coerência para a proposição de medidas mitigadoras.

Mas há também aprendizados gerados com a experiência internacional e que poderiam ser convertidos em inovações na experiência brasileira. Em particular, há dois dispositivos vistos no decorrer deste artigo que poderiam resultar em aperfeiçoamentos e um terceiro sobre o qual seria preciso maiores reflexões, confrontando a experiência brasileira à de outros países. $\mathrm{O}$ primeiro dispositivo diz respeito à autonomia dos estudos de impacto ambiental perante os proponentes dos empreendimentos sob avaliação. No caso brasileiro, como foi visto, o fato de que a apresentação do estudo é de responsabilidade do próprio proponente tem gerado um viés nas avaliações. Isto é, em vez de um efetivo balanço dos efeitos potenciais do empreendimento, as análises são orientadas para a identificação das medidas necessárias a tornar a iniciativa viável. Seria salutar que fossem buscados mecanismos voltados a conferir maior independência aos estudos ou a favorecer a elaboração de análises contrastadas, capazes de melhor subsidiar o processo decisório. Garantir que os estudos sejam feitos por organismos independentes ou para que organizações contrárias aos empreendimentos possam elaborar relatórios alternativos, considerados com igual peso no processo decisório, é algo que certamente traria avanços na qualificação das decisões tomadas.

$\mathrm{O}$ segundo dispositivo diz respeito às formas de consulta. Também foi dito no momento de expor a experiência brasileira que as audiências públicas, hoje o mecanismo privilegiado de consulta, acabam por revelar-se um momento quase formal, voltado à explicitação de posições a favor ou contra o empreendimento, em vez de um debate voltado ao aprimoramento do entendimento sobre os conflitos sociais e ambientais em tela. $\mathrm{Na}$ experiência internacional, destacadamente a realização de painéis de aprofundamento da compreensão e da discussão sobre estes conflitos ou para mediação de posições é algo que poderia inspirar a introdução de mecanismos similares para o caso brasileiro. Além de permitir melhor entendimento das polêmicas e controvérsias envolvidas, tais mecanismos poderiam favorecer a participação de segmentos sociais não identificados previamente com uma das posições em disputa, ampliando, por aí, a base social de interesses envolvida no processo decisório.

O terceiro dispositivo, no qual a experiência brasileira difere das demais vistas no corpo do artigo, é a concessão de uma licença única ou desmembrada por fases do empreendimento. Se por um lado a experiência 
brasileira permite maior adaptação das medidas à evolução de cada fase, por outro, na prática, tem tornado quase irreversível o funcionamento de um empreendimento após a concessão da licença para as etapas prévia e de instalação. A concessão de uma licença única, como acontece nos demais países, por outro lado, pode garantir maior coerência e consistência ao processo de licenciamento, mas também pode enrijecer excessivamente os procedimentos. Este é um dispositivo sobre o qual seria preciso conhecer em maiores detalhes casos específicos de licenciamento para uma melhor avaliação.

Mais importante do que os três dispositivos elencados acima é a constatação de que há, na experiência internacional, aprendizados que podem fazer avançar de maneira incremental a sofisticação e a eficiência das regras para a realização de grandes empreendimentos

\section{Referências}

Abramovay, R. Responsabilidade socioambiental: as empresas no meio ambiente, o meio ambiente nas empresas. In: Veiga, José Eli (Coord.). Economia socioambiental. 1. ed. São Paulo: SENAC, 2010. p. 335-356.

Acselrad, H. As práticas espaciais e o campo dos conflitos ambientais. In: (Coord.). Conflitos ambientais no Brasil. Rio de Janeiro: Fundação Heinrich Böll/Relume Dumará, 2004.

Bermann, C. Impasses e controvérsias da hidreletricidade. Estudos Avançados, São Paulo, 21 (59), 139-153, 2007.

Beyer, S. Environmental Law and Policy in the People's Republic of China. Oxford University Press. Chinese Journal of International Law, 5(1), 185-211, 2006.

Brasil. Decreto n. ${ }^{\circ} 9$ de 03 de dezembro de 1987. Regulamenta as Audiências Públicas no Processo de Licenciamento Ambiental. Brasília, 1987.

. Plano Nacional de Expansão de Energia 2030. Ministério das Minas e Energia/Empresa de Pesquisa Energética - EPE. Rio de Janeiro: EPE, 2006.

Manual de Inventário Hidroelétrico de Bacias Hidrográficas. Ministério de Minas e Energia - MME/Secretaria de Planejamento e Desenvolvimento Energético/Centro de Pesquisas de Energia Elétrica - CEPEL. Edição 2007. Rio de Janeiro, RJ, 2007. hidrelétricos e, por aí, é possível conferir maior sustentabilidade aos investimentos em energia no país. Isso não pode ser feito com ingenuidade, afinal, a aprendizagem institucional não é uma mera questão técnica ou cognitiva. As decisões pela introdução de mudanças deste tipo refletem sempre interesses e o balanço de poder entre forças sociais identificadas com o aperfeiçoamento ou com a estagnação (quando não com a revisão) dos dispositivos atuais de regulação ambiental. Apesar disto, não há dúvida de que aumentar a base de conhecimento sobre como são feitos os processos de licenciamento, no Brasil e em outros países, é um instrumento necessário para ampliar as bases em torno das quais se faz o debate público sobre estes marcos institucionais. As páginas anteriores são uma pequena contribuição nesta direção.

. Resenha Energética Brasileira: exercício de 2010 (preliminar). Ministério de Minas e Energia - MME/Empresa de Pesquisa Energética - EPE. Rio de Janeiro: EPE, 2011.

Canadá. Hydropower for a Sustainable and Renewable Energy Mix. Submission to the Council of Energy Ministers. Canadian Hydropower Association - CHA. Whitehourse, Yukon, Canadá, 2006.

. Romaine River Hydroelectric Complex Development Project: investigation and public hearing report. Bureau d'Audiences Publiques sur l'Environnement/Canadian Environmental Assessment Agency. Québec, Canadá, 2009.

EUA. Key World Energy Statistics. United States: International Energy Agency - IEA, 2010.

. World Energy Outlook 2012. United States: International Energy Agency - IEA, 2012a.

Key World Energy Statistics 2012. United States: International Energy Agency - IEA, 2012 b.

. A citizen's guide to the NEPA: having your voice heard. United States: Council of Environmental Quality - CEQ. Executive Office of the President, 2007.

Hinrichs, R.; Kleinbach, M.; Reis, L. B. Energia e meio ambiente. Tradução da quarta edição norte-americana. Cengage Learning. 2010. 
Hong, S.; Cosbey, A.; Savage, M. China's Electrical Power Sector, Environmental Protection and Sustainable Trade. In: Halle, M.; Guoqiang, L. (Coord.). Elements of a Sustainable Trade Strategy for China. International Institute for Sustainable Development. Manitoba, Canadá, 2009. p. 61-93.

La Rovere, E. L. Instrumentos de planejamento e gestão ambiental para a Amazônia, cerrado e pantanal: demandas e propostas; metodologia de avaliação de impacto ambiental. Brasília: IBAMA, 2001.

Li, J. C. Environmental Impact Assessments in Developing Countries: An Opportunity for Greater Environmental Security? Working Paper n. 4. USA: United States Agency for International Development - USAID/Foundation for Environmental Security \& Sustainability - FEES, 2008.

Mc Elwee, C.; Sanders, S.; Dempsey, L. L. P. The Environmental Impact Assessment in China: The first step toward compliant in operations. International Environmental Law Committee Newsletter, 10(4), 2008.

Mendell, A. Four types of impact assessment used in Canada. Preliminary Version. September 2010. National Collaborating Centre for Healthy Public Policy. Institut National de Santé Publique, Québec. Canadá, 2010.

Morgan, R. K. Environmental impact assessment: the state of the art. Impact Assessment and Project Appraisal, 30(1), 5-14, March 2012.

Ortolano, L.; Cushing, K. K. Grand Coulee Dam and the Columbia Basin Project. Final Report.Prepared for the World Commission. United States, 2000.

Raadal, H. L.; Gagnon, L.; Modahl, I. S.; Hanssen, O. J. Life cicle greenhouse gas (GHG) emissions from the generation of wind and hydro power. Renewable and Sustainable Energy Reviews, 15, 3417-3422, 2011.

Reis, L. B. Matrizes energéticas: conceitos e usos em gestão e planejamento. Arlindo Phillip Jr. (Org.). São Paulo: EDUSP, 2011. (Série Sustentabilidade)
Rocha, E. C.; Canto, J. L.; Pereira, P. C. Avaliação de impactos ambientais nos países do Mercosul. Ambiente \& Sociedade, Campinas, SP, 8(2), 2005.

Sánchez, L. E. Avaliação de impacto ambiental: conceitos e métodos. 1. ed. São Paulo: Oficina dos Textos, 2008.

Sevá, O. Estranhas catedrais. Notas sobre o capital hidrelétrico, a natureza e a sociedade. Revista Cienc. Cult., 60(3), 44-50, 2008.

Silva L. F.; Soares A. J. S. Análise das experiências internacionais em avaliação de impacto ambiental. In: Anais do XLII Congresso da SOBER. Cuiabá, MT, 2004.

Steinhurst, W.; Knight, P.; Schultz, M. Hydropower greenhouse gas emissions: state of the research. Synapse Energy Economics, Inc. Cambridge, MA, 2012.

Truchon, M. The future of hydropower. Session IV: Energy Diversification. Bi-Regional WEC Forum. North America, Latin America, the Caribbean Mexico City, June 62006.

Walter, A. As mudanças climáticas e as questões energéticas. Revista Multiciência, Campinas, SP, 8, 2007.

WCD. Dams and Development: A New Framework for Decision Making. Earthscan, London, 2000.

Webb, W.; Sigal, L. L. Strategic environmental assessment in the United States. Project Appraisal, 7(3), 137-141, September 1992 .

Zhao, Y. Public participation in China's EIA Regime: Rhetoric or Reality? Journal of Environmental Law. Published by Oxford University Press, 2010.

Zhouri, A.; Oliveira, R. Desenvolvimento, conflitos sociais e violência no Brasil Rural: o caso das usinas hidrelétricas. Ambiente \& Sociedade, Campinas, SP, X(2), 119-135, 2007.

Zhu, T.; Lam, K.-C. Environmental Impact Assessment in China. Research Center of Strategic Environmental Assessment - Nankai University/Centre of Strategic Environmental Assessment for China - The Chinese University of Hong Kong, 2009. 